\title{
A first-principles study of chlorine adsorption characteristics on $\alpha-\mathrm{Cr}_{2} \mathrm{O}_{3}$ nanostructures
}

\author{
V NAGARAJAN and R CHANDIRAMOULI* \\ School of Electrical \& Electronics Engineering, SASTRA University, Tirumalaisamudram, Thanjavur \\ 613 401, India \\ e-mail: rcmoulii@gmail.com
}

MS received 3 April 2015; revised 15 July 2015; accepted 15 July 2015

\begin{abstract}
The structural stability, electronic and adsorption properties of chlorine on pristine, Zn, W and Nsubstituted $\alpha-\mathrm{Cr}_{2} \mathrm{O}_{3}$ nanostructures are successfully optimized and simulated with the help of density functional theory utilizing B3LYP/ LanL2DZ basis set. The structural stability of $\alpha-\mathrm{Cr}_{2} \mathrm{O}_{3}$ nanostructures are discussed in terms of formation energy. The electronic properties of pristine, $\mathrm{Zn}, \mathrm{W}$ and $\mathrm{N}$-substituted $\alpha-\mathrm{Cr}_{2} \mathrm{O}_{3}$ nanostructures are described with HOMO-LUMO gap, ionization potential and electron affinity. Dipole moment and point symmetry group of pristine, $\mathrm{Zn}, \mathrm{W}$ and $\mathrm{N}$-substituted $\alpha-\mathrm{Cr}_{2} \mathrm{O}_{3}$ nanostructures are reported. The adsorption characteristics of $\mathrm{Cl}_{2}$ on $\alpha-\mathrm{Cr}_{2} \mathrm{O}_{3}$ materials are investigated and the prominent adsorption sites of $\mathrm{Cl}_{2}$ on $\alpha-\mathrm{Cr}_{2} \mathrm{O}_{3}$ nanostructures are identified. The important parameters such as adsorbed energy, energy gap, average energy gap variation and Mulliken population analysis are used to find the favourable adsorption site of $\mathrm{Cl}_{2}$ on $\alpha-\mathrm{Cr}_{2} \mathrm{O}_{3}$ base material. The substitution of impurities such as $\mathrm{Zn}, \mathrm{W}$ and $\mathrm{N}$ in $\alpha-\mathrm{Cr}_{2} \mathrm{O}_{3}$ nanostructures enhances the $\mathrm{Cl}_{2}$ adsorption characteristics in the mixed gas environment.
\end{abstract}

Keywords. Chromium oxide; nanostructures; adsorption; Mulliken population; adsorbed energy.

\section{Introduction}

In recent years, research is focused on metal oxide semiconductor (MOX) based chemiresistive gas sensors. ${ }^{1}$ The surface reactivity of MOX nanostructures depends on the binding species, which is influenced by change in electron affinity and surface potential variations of adsorbent. The transfer of electrons between the adsorbent and base material leads to the change in the resistance of the thin film. Moreover, the exchange of charge carriers can be measured using electrical resistance measurement, whereas the surface potential variation can be sensed by change in the work function. The combined variation of resistance and work function provides the estimation of surface reactivity of gas on the base material. Besides the synthesis of MOX with control on size, shape, surface-to-volume ratio enhances the sensitivity of base material towards target gas. ${ }^{2,3}$ The main requirement of sensitivity, selectivity, response towards target gas is important criterion in chemiresistive based MOX gas sensors. Generally, n-type transition metal oxide semiconductors, such as, $\mathrm{WO}_{3}, \mathrm{SnO}_{2}, \mathrm{ZnO}$ and $\operatorname{In}_{2} \mathrm{O}_{3}$ have been used in commercial applications $\mathrm{s}^{4,5}$ owing to the fact that it is extensively studied for their gas sensing mechanism. On the other hand, there is

*For correspondence not much work reported in p-type semiconductor. One among the p-type semiconductor is chromium oxide $\left(\mathrm{Cr}_{2} \mathrm{O}_{3}\right) . \mathrm{Cr}_{2} \mathrm{O}_{3}$ finds its potential application in optical coating, infrared sensors and catalytic reactions. The experimental energy band gap value for $\mathrm{Cr}_{2} \mathrm{O}_{3}$ is $\sim 3.4 \mathrm{eV}^{6-9}$ However, pristine $\mathrm{Cr}_{2} \mathrm{O}_{3}$ was reported with poor gas sensitivity. The gas sensing properties of the materials can be enhanced with surface activation or substitution of impurities into pristine $\mathrm{Cr}_{2} \mathrm{O}_{3}$.

Chlorine $\left(\mathrm{Cl}_{2}\right)$ is one of the hazardous gases, which is an exhaust gas from industries related with textiles, plastics, pharmaceuticals, household cleaning products, agrochemicals and water purification, etc. According to Occupational Safety and Health Administration (OSHA) standard the permissible exposure limit (PEL) for chlorine is 1 part per million (ppm) for a period of 15 minutes. $\mathrm{Cl}_{2}$ gas is harmful to life, beyond the threshold limit; $\mathrm{Cl}_{2}$ produces skin irritation, sensory irritation, suffocation, bronchospasm, etc. ${ }^{10}$ This necessitated the detection of toxic $\mathrm{Cl}_{2}$. Chromium oxide exhibits in different phases namely rutile $\mathrm{CrO}_{2}$, corundum $\mathrm{Cr}_{2} \mathrm{O}_{3}$, three-dimensional framework $\mathrm{Cr}_{5} \mathrm{O}_{12}$, etc. Maldonado et al. ${ }^{11}$ studied the structure, electronic and magnetic properties of Ca-doped chromium oxide using density functional theory method. Blacklocks et al. ${ }^{12}$ reported XAS study of defect structure in Ti-doped $\alpha-\mathrm{Cr}_{2} \mathrm{O}_{3}$. Density functional theory (DFT) is one of the most 
prominent methods to investigate the adsorption properties of compounds and gases. ${ }^{13}$ In this regard, literature survey was conducted using CrossRef metadata search and it is revealed that there are not much works reported based on DFT methods to investigate the adsorption properties of $\mathrm{Cl}_{2}$ on $\alpha-\mathrm{Cr}_{2} \mathrm{O}_{3}$ nanostructures. The motivation behind the present work is to enhance $\mathrm{Cl}_{2}$ adsorption characteristics on $\alpha-\mathrm{Cr}_{2} \mathrm{O}_{3}$ nanostructures with incorporation of suitable impurities such as $\mathrm{Zn}, \mathrm{W}$ and $\mathrm{N}$. The novel aspect of this work is to study the adsorption characteristics of $\mathrm{Cl}_{2}$ on different sites of $\alpha-\mathrm{Cr}_{2} \mathrm{O}_{3}$ nanostructures with the substitution of $\mathrm{Zn}, \mathrm{W}$ and $\mathrm{N}$ and the results are reported.

\section{Computational Methods}

The pristine, $\mathrm{Zn}, \mathrm{W}$ and $\mathrm{N}$-substituted $\alpha-\mathrm{Cr}_{2} \mathrm{O}_{3}$ nanostructures are optimized successfully using Gaussian 09 package. ${ }^{14}$ The adsorption characteristics of $\mathrm{Cl}_{2}$ gas on $\alpha-\mathrm{Cr}_{2} \mathrm{O}_{3}$ base material is also investigated with Gaussian package. In the present work, DFT method is used along with Becke's three-parameter hybrid functional in combination with Lee-Yang-Parr correlation functional (B3LYP) with the help of LanL2DZ basis set. ${ }^{15}$ The choice of suitable basis set is one of the important criterions for studying $\alpha-\mathrm{Cr}_{2} \mathrm{O}_{3}$ nanostructures. Since the atomic numbers of chromium and oxygen are twenty four and eight, respectively, LanL2DZ basis set is a good choice among other basis sets. It gives an optimum output with pseudo potential approximation. ${ }^{16,17}$ The HOMO-LUMO gap and density of states spectrum (DOS) of $\alpha-\mathrm{Cr}_{2} \mathrm{O}_{3}$ nanostructures is recorded using Gauss Sum 3.0 package. ${ }^{18}$ The energy convergence is attained in the range of $10^{-5} \mathrm{eV}$ while optimizing $\alpha-\mathrm{Cr}_{2} \mathrm{O}_{3}$ nanostructures.

\section{Results and Discussion}

The main objective of this work is to study the ionization potential (IP), formation energy, HOMO-LUMO gap, electron affinity (EA), dipole moment and the adsorption characteristics of $\mathrm{Cl}_{2}$ gas on $\alpha-\mathrm{Cr}_{2} \mathrm{O}_{3}$ base material with the substitution of impurities, such as, $\mathrm{Zn}$,
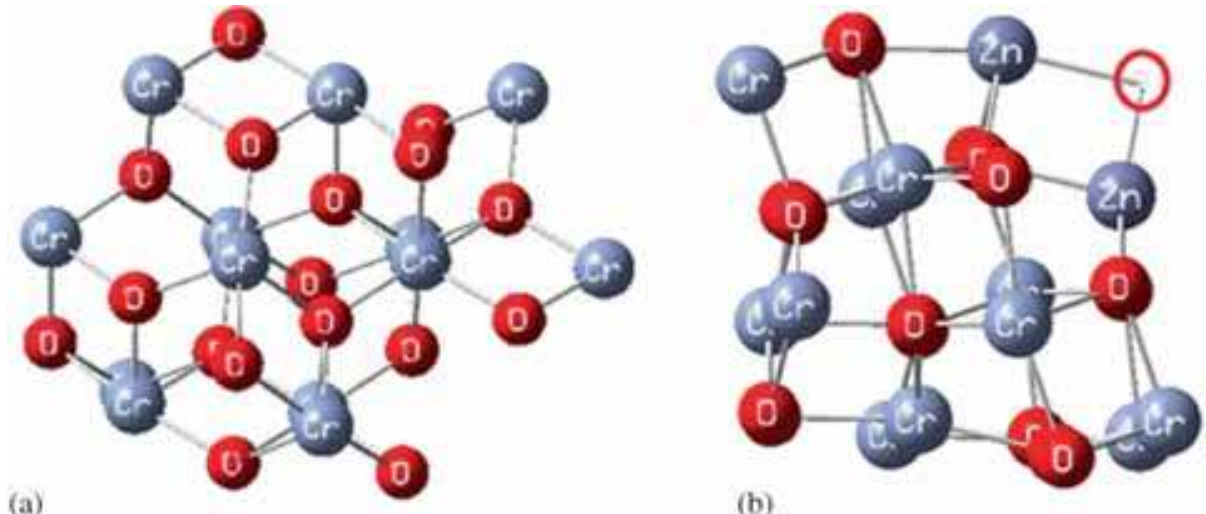

(b)
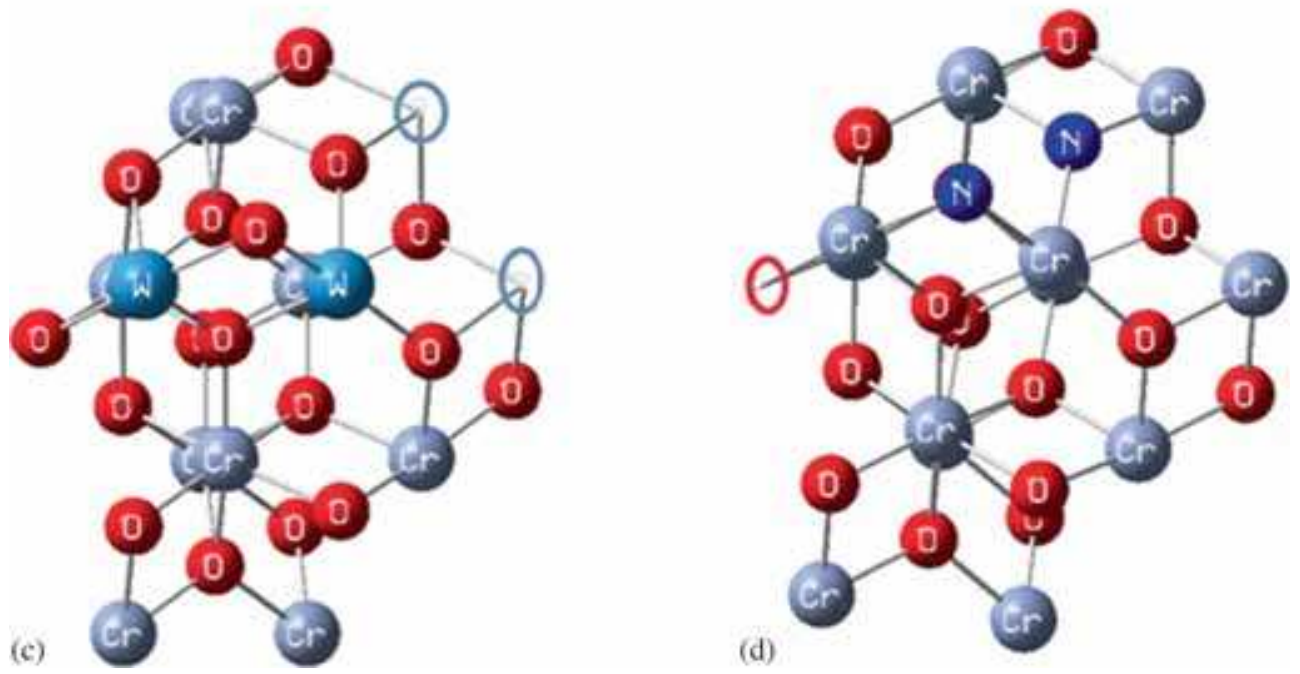

Figure 1. (a) Pristine $\alpha-\mathrm{Cr}_{2} \mathrm{O}_{3}$ nanostructure; (b) $\mathrm{Zn}$-substituted $\alpha-\mathrm{Cr}_{2} \mathrm{O}_{3}$ nanostructure; (c) W-substituted $\alpha-\mathrm{Cr}_{2} \mathrm{O}_{3}$ nanostructure; (d) N-substituted $\alpha-\mathrm{Cr}_{2} \mathrm{O}_{3}$ nanostructure. 
$\mathrm{W}$ and $\mathrm{N}$ in $\alpha-\mathrm{Cr}_{2} \mathrm{O}_{3}$ nanostructures. The substitution of impurities on $\alpha-\mathrm{Cr}_{2} \mathrm{O}_{3}$ nanostructure influences the conductivity enormously. This infers that the adsorption properties of $\mathrm{Cl}_{2}$ on $\alpha-\mathrm{Cr}_{2} \mathrm{O}_{3}$ nanostructures can be improved with the incorporation of dopant. Figure 1 (a) - (d) represents the nanostructures of pristine, $\mathrm{Zn}$, $\mathrm{W}$ and $\mathrm{N}$-substituted $\alpha-\mathrm{Cr}_{2} \mathrm{O}_{3}$ nanostructures, respectively. The structure of $\alpha-\mathrm{Cr}_{2} \mathrm{O}_{3}$ is built from International Centre for Diffraction Data (ICDD) card number: 06-0504. The pristine $\alpha-\mathrm{Cr}_{2} \mathrm{O}_{3}$ nanostructure has seventeen oxygen atoms and thirteen chromium atoms. $\mathrm{Zn}$ substituted $\alpha-\mathrm{Cr}_{2} \mathrm{O}_{3}$ nanostructure contains sixteen $\mathrm{O}$ atoms, eleven $\mathrm{Cr}$ atoms and two $\mathrm{Cr}$ atoms are replaced with equivalent two $\mathrm{Zn}$ atoms. Similarly, W-substituted $\alpha-\mathrm{Cr}_{2} \mathrm{O}_{3}$ nanostructure has seventeen $\mathrm{O}$ atoms, nine $\mathrm{Cr}$ atoms and two $\mathrm{Cr}$ atoms are replaced with two $\mathrm{W}$ atoms. N-substituted $\alpha-\mathrm{Cr}_{2} \mathrm{O}_{3}$ nanostructure contains fourteen $\mathrm{O}$ atoms, thirteen $\mathrm{Cr}$ atoms and two $\mathrm{O}$ atoms are replaced with two $\mathrm{N}$ atoms. Moreover, Dutta et al. have reported $\mathrm{CO}$ adsorption on ionic $\mathrm{Pt}, \mathrm{Pd}$ and $\mathrm{Cu}$ sites in $\mathrm{Ce}_{0.98} \mathrm{M}_{0.02} \mathrm{O}_{2-\delta} \cdot{ }^{19}$ In order to balance the charge in the nanostructure, positive or negative ions should be removed. In a similar way, to maintain charge balance in impurity substituted $\alpha-\mathrm{Cr}_{2} \mathrm{O}_{3}$ nanostructures, some of the positive or negative ions are removed. Besides, to make charge balance in $\mathrm{Zn}$-substituted $\alpha$ $\mathrm{Cr}_{2} \mathrm{O}_{3}$ nanostructure, one oxygen vacancy has been created. Since, the oxidation state of $\mathrm{Cr}$ is +3 state and $\mathrm{Zn}$ is +2 state. Thus, for substitution of every two $\mathrm{Zn}$ atom in $\alpha-\mathrm{Cr}_{2} \mathrm{O}_{3}$ nanostructure, one oxygen vacancy must be created. Similarly, in the case of W-substituted $\alpha-\mathrm{Cr}_{2} \mathrm{O}_{3}$ nanostructures, two $\mathrm{Cr}$ atoms are removed and for $\mathrm{N}$-substituted $\alpha-\mathrm{Cr}_{2} \mathrm{O}_{3}$ nanostructures, one oxygen vacancy is created to maintain charge balance in $\alpha-\mathrm{Cr}_{2} \mathrm{O}_{3}$ base material.

The reason behind the selection of $\mathrm{Zn}$ atom is $\mathrm{Cr}$ and $\mathrm{Zn}$ belongs to fourth period transition metals. Moreover, $\mathrm{W}$ is substituted in place of $\mathrm{Cr}$, since $\mathrm{Cr}$ and $\mathrm{W}$ belongs to group VIB elements. $\mathrm{N}$ atom has one electron deficient than $\mathrm{O}$ atom, which will increase the $\mathrm{p}$ type behaviour in the base material. The substitution of $\mathrm{Zn}, \mathrm{W}$ and $\mathrm{N}$ completely modifies the conducting properties of $\alpha-\mathrm{Cr}_{2} \mathrm{O}_{3}$ nanostructures.

\subsection{Structural stability and electronic properties of $\alpha-\mathrm{Cr}_{2} \mathrm{O}_{3}$ nanostructures}

The structural stability of pristine, $\mathrm{Zn}, \mathrm{W}$ and $\mathrm{N}$ substituted $\alpha-\mathrm{Cr}_{2} \mathrm{O}_{3}$ nanostructures are described with formation energy as shown in equation 1 ,

$$
\begin{aligned}
\mathrm{E}_{\text {form }}= & \mathrm{E}\left(\alpha-\mathrm{Cr}_{2} \mathrm{O}_{3} \text { nanostructure }\right)-\mathrm{x} \mathrm{E}(\mathrm{Cr}) \\
& -\mathrm{yE}(\mathrm{O})-\mathrm{z} \mathrm{E}(\text { dopant })
\end{aligned}
$$

where $\mathrm{E}\left(\alpha-\mathrm{Cr}_{2} \mathrm{O}_{3}\right.$ nanostructure $)$ refers the total energy of $\alpha-\mathrm{Cr}_{2} \mathrm{O}_{3}$ nanostructures, $\mathrm{E}(\mathrm{Cr}), \mathrm{E}(\mathrm{O})$ and $\mathrm{E}$ (dopant) represents the corresponding energy of isolated $\mathrm{Cr}$, $\mathrm{O}$ and dopant atoms namely $\mathrm{Zn}, \mathrm{W}$ and $\mathrm{N}$. Meanwhile, $\mathrm{x}, \mathrm{y}$ and $\mathrm{z}$ represents the number of $\mathrm{Cr}, \mathrm{O}$ and dopant atoms, respectively. The dipole moment, point group and formation energies of pristine, $\mathrm{Zn}, \mathrm{W}$ and $\mathrm{N}$-substituted $\alpha-\mathrm{Cr}_{2} \mathrm{O}_{3}$ nanostructures are tabulated in table 1. The formation energy of pristine, $\mathrm{Zn}, \mathrm{W}$ and $\mathrm{N}$-substituted $\alpha-\mathrm{Cr}_{2} \mathrm{O}_{3}$ nanostructures are -162.93 , $-146.88,-144.16$ and $-161.84 \mathrm{eV}$, respectively. Before investigating the adsorption characteristics, the stability of the $\alpha-\mathrm{Cr}_{2} \mathrm{O}_{3}$ material must be studied. The stability of $\alpha-\mathrm{Cr}_{2} \mathrm{O}_{3}$ base material decreases with the substitution of $\mathrm{Zn}, \mathrm{W}$ and $\mathrm{N}$ atoms as dopants which arise due to decrease in formation energy. However, the electronic properties of $\alpha-\mathrm{Cr}_{2} \mathrm{O}_{3}$ nanostructures are influenced with substitution impurities. The dipole moment (DP) gives significance about the distribution of charges in $\alpha-\mathrm{Cr}_{2} \mathrm{O}_{3}$ nanostructure. The DP values for pristine, $\mathrm{Zn}, \mathrm{W}$ and $\mathrm{N}$-substituted $\alpha-\mathrm{Cr}_{2} \mathrm{O}_{3}$ nanostructure are found to be $8.45,10.94,30.41$ and 7.49 Debye, respectively. Moreover, the uniform charge distribution is noticed in pristine, $\mathrm{Zn}$ and $\mathrm{N}$-substituted $\alpha-\mathrm{Cr}_{2} \mathrm{O}_{3}$ nanostructure due to low value of DP. Furthermore, a uniform charge distribution in $\alpha-\mathrm{Cr}_{2} \mathrm{O}_{3}$ nanostructure can be achieved with the substitution of $\mathrm{N}$ in the proper site. In contrast, the substitution of $\mathrm{W}$ in $\alpha-\mathrm{Cr}_{2} \mathrm{O}_{3}$ results in high value of DP. Besides, $\mathrm{C}_{1}$ point group is observed for all $\alpha-\mathrm{Cr}_{2} \mathrm{O}_{3}$ nanostructures, which exhibit only identity operation.

The electronic properties of pristine, $\mathrm{Zn}, \mathrm{W}$ and Nsubstituted $\alpha-\mathrm{Cr}_{2} \mathrm{O}_{3}$ nanostructures are illustrated in terms of highest occupied molecular orbital (HOMO) and lowest unoccupied molecular orbital (LUMO). ${ }^{20}$ The HOMO-LUMO gap for pristine, $\mathrm{Zn}, \mathrm{W}$ and $\mathrm{N}$ substituted $\alpha-\mathrm{Cr}_{2} \mathrm{O}_{3}$ nanostructures are 3.72, 4.02, 3.09 and $3.74 \mathrm{eV}$, respectively. The experimental energy gap value is reported as $3.4 \mathrm{eV}$, which almost matches with the obtained theoretical value of $3.72 \mathrm{eV}$ for pristine $\alpha$ $\mathrm{Cr}_{2} \mathrm{O}_{3}$. Moreover, the energy gap variation differs with respect to the choice of basis set. Theoretically, DFT method is more probably related to ground state, the excited electronic state may be underestimated. However, the HOMO-LUMO gaps of $\mathrm{Cl}_{2}$ adsorbed on $\alpha$ $\mathrm{Cr}_{2} \mathrm{O}_{3}$ nanostructures are relatively compared with its isolated counterpart. The HOMO-LUMO gap of $\alpha$ $\mathrm{Cr}_{2} \mathrm{O}_{3}$ nanostructures increases for $\mathrm{Zn}$ and $\mathrm{N}$ substitution and in contrast, HOMO-LUMO gap decreases for W substitution. These variations in HOMO-LUMO gap arises due to orbital overlapping of $\mathrm{Zn}, \mathrm{W}$ and $\mathrm{N}$ with $\mathrm{Cr}$ and $\mathrm{O}$ atoms in $\alpha-\mathrm{Cr}_{2} \mathrm{O}_{3}$ nanostructure. The HOMO, LUMO level and energy gap of $\alpha-\mathrm{Cr}_{2} \mathrm{O}_{3}$ nanostructures 
Table 1. Calculated energy, dipole moment and point group of $\alpha-\mathrm{Cr}_{2} \mathrm{O}_{3}$ nanostructures.

\begin{tabular}{lccc}
\hline Nanostructures & $\begin{array}{c}\text { Formation } \\
\text { energy (eV) }\end{array}$ & $\begin{array}{c}\text { Dipole moment } \\
\text { (Debye) }\end{array}$ & $\begin{array}{c}\text { Point } \\
\text { Group }\end{array}$ \\
\hline pristine $\alpha-\mathrm{Cr}_{2} \mathrm{O}_{3}$ nanostructure & -162.928 & 8.45 & $\mathrm{C}_{1}$ \\
Zn-substituted $\alpha-\mathrm{Cr}_{2} \mathrm{O}_{3}$ nanostructure & -146.88 & 10.94 & $\mathrm{C}_{1}$ \\
W-substituted $\alpha-\mathrm{Cr}_{2} \mathrm{O}_{3}$ nanostructure & -144.16 & 30.41 & $\mathrm{C}_{1}$ \\
N-substituted $\alpha-\mathrm{Cr}_{2} \mathrm{O}_{3}$ nanostructure & -161.84 & 7.49 & $\mathrm{C}_{1}$ \\
\hline
\end{tabular}

Table 2. HOMO - LUMO gap of $\alpha-\mathrm{Cr}_{2} \mathrm{O}_{3}$ nanostructures.

\begin{tabular}{lccc}
\hline Nanostructures & $\mathrm{HOMO}(\mathrm{eV})$ & $\mathrm{LUMO}(\mathrm{eV})$ & $\mathrm{E}_{\mathrm{g}}(\mathrm{eV})$ \\
\hline pristine $\alpha$ - $\mathrm{Cr}_{2} \mathrm{O}_{3}$ nanostructure & -5.64 & -1.92 & 3.72 \\
$\mathrm{Zn}$-substituted $\alpha-\mathrm{Cr}_{2} \mathrm{O}_{3}$ nanostructure & -5.37 & -1.35 & 4.02 \\
W-substituted $\alpha-\mathrm{Cr}_{2} \mathrm{O}_{3}$ nanostructure & -6.3 & -3.21 & 3.09 \\
N-substituted $\alpha-\mathrm{Cr}_{2} \mathrm{O}_{3}$ nanostructure & -5.03 & -1.29 & 3.74 \\
\hline
\end{tabular}

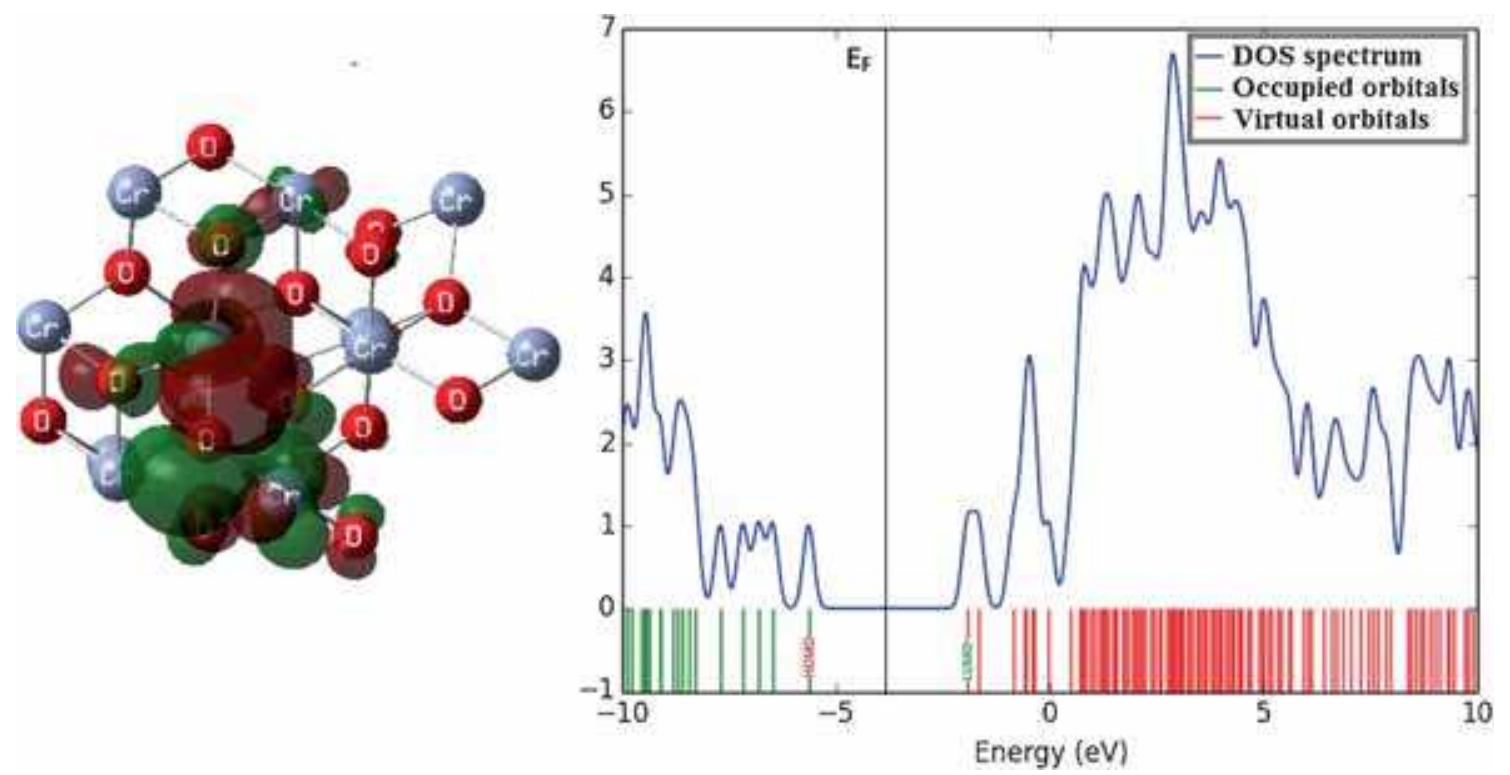

Figure 2. HOMO-LUMO gap and density of states of pristine $\alpha-\mathrm{Cr}_{2} \mathrm{O}_{3}$ nanostructures.

are tabulated in table 2. With the help of density of states (DOS) spectrum, localization of charges in various energy intervals for $\alpha-\mathrm{Cr}_{2} \mathrm{O}_{3}$ nanostructures can be illustrated. The DOS spectrum and visualization of HOMO-LUMO gap of $\alpha-\mathrm{Cr}_{2} \mathrm{O}_{3}$ nanostructure are shown in figure 2. The HOMO-LUMO visualization and density of states of Zn-substituted $\alpha-\mathrm{Cr}_{2} \mathrm{O}_{3}, \mathrm{~W}$ substituted $\alpha-\mathrm{Cr}_{2} \mathrm{O}_{3}$ and $\mathrm{N}$-substituted $\alpha-\mathrm{Cr}_{2} \mathrm{O}_{3}$ nanostructures are shown in supplementary information figure S2 a-c, respectively. In the present work, for all $\alpha-\mathrm{Cr}_{2} \mathrm{O}_{3}$ nanostructures, localization of charges are recorded to be more in virtual orbital, which is observed with more peak maxima. These peak maxima in $\alpha$ $\mathrm{Cr}_{2} \mathrm{O}_{3}$ nanostructures arise due to the orbital overlapping of $\mathrm{Cr}$ atoms with $\mathrm{O}$ atoms in $\alpha-\mathrm{Cr}_{2} \mathrm{O}_{3}$ base material. Besides, the peak maxima in virtual orbitals of
$\alpha-\mathrm{Cr}_{2} \mathrm{O}_{3}$ base material are more feasible for adsorption of gas molecules, since the transition of electrons takes place easily between virtual orbital of $\alpha-\mathrm{Cr}_{2} \mathrm{O}_{3}$ and target gas molecules.

The electronic properties of $\alpha-\mathrm{Cr}_{2} \mathrm{O}_{3}$ nanostructure can also be illustrated with the help of ionization potential (IP) and electron affinity (EA). ${ }^{21,22}$ Figure 3 represents IP and EA of $\alpha-\mathrm{Cr}_{2} \mathrm{O}_{3}$ nanostructures. Generally IP depicts the quantity of energy required to remove electron from $\alpha-\mathrm{Cr}_{2} \mathrm{O}_{3}$ nanostructures and the EA depicts the energy variation owing to addition of electron in $\alpha-\mathrm{Cr}_{2} \mathrm{O}_{3}$ nanostructures. The high value of IP implies that the electrons are perfectly bounded to nucleus in $\alpha-\mathrm{Cr}_{2} \mathrm{O}_{3}$ nanostructure. Different trends are observed on both ionization potential and electron affinity of $\alpha-\mathrm{Cr}_{2} \mathrm{O}_{3}$ nanostructure. Relatively, less energy is 


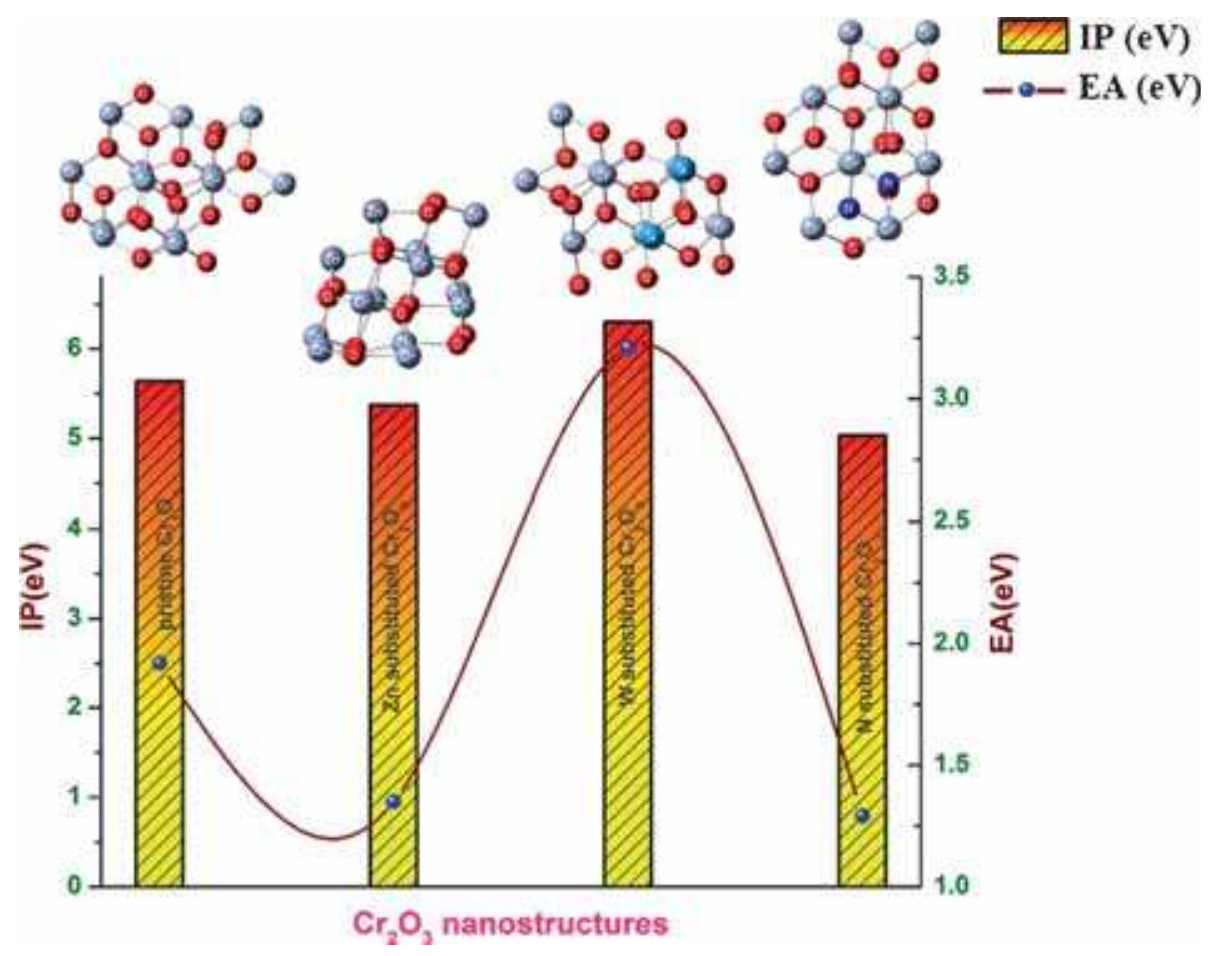

Figure 3. IP and EA of $\alpha-\mathrm{Cr}_{2} \mathrm{O}_{3}$ nanostructure.

required to remove electrons from $\alpha-\mathrm{Cr}_{2} \mathrm{O}_{3}$ nanostructure due to the substitution of $\mathrm{Zn}$ and $\mathrm{N}$ atoms. However, W substitution on $\alpha-\mathrm{Cr}_{2} \mathrm{O}_{3}$ nanostructure gives rise to high value of IP. EA is one of the important criterions in plasma physics and chemical sensors. The EA values of pristine, $\mathrm{Zn}, \mathrm{W}$ and $\mathrm{N}$-substituted $\alpha$ $\mathrm{Cr}_{2} \mathrm{O}_{3}$ nanostructures are 1.92, 1.35, 3.21 and $1.29 \mathrm{eV}$, respectively.

\subsection{Adsorption characteristics of $\mathrm{Cl}_{2}$ on $\alpha-\mathrm{Cr}_{2} \mathrm{O}_{3}$ nanostructures}

In the beginning of $\mathrm{Cl}_{2}$ adsorption study on $\alpha-\mathrm{Cr}_{2} \mathrm{O}_{3}$, $\mathrm{Cl}_{2}$ molecule should be investigated in gas phase. The bond length between two chlorine atoms is $1.98 \AA$ and the bond length between chromium and oxygen atom in $\alpha-\mathrm{Cr}_{2} \mathrm{O}_{3}$ is $1.82 \AA$. During the optimization of $\alpha-\mathrm{Cr}_{2} \mathrm{O}_{3}$ nanostructure, these bond lengths are utilized. Figure 4(a) refers the adsorption of $\mathrm{Cl}$ atom in $\mathrm{Cl}_{2}$ molecules adsorbed on $\mathrm{Cr}$ atom in pristine $\alpha-\mathrm{Cr}_{2} \mathrm{O}_{3}$ nanostructure and it is denoted by position A. Figure 4 (b) depicts the adsorption of $\mathrm{Cl}$ atom in $\mathrm{Cl}_{2}$ gas molecule adsorbed on $\mathrm{O}$ atom of pristine $\alpha-\mathrm{Cr}_{2} \mathrm{O}_{3}$ nanostructure and it is mentioned as position $\mathrm{B}$. The other positions are represented as figure S4 (c) in Supplementary Information.

The adsorbed energy of $\mathrm{Cl}_{2}$ gas molecule on $\alpha-\mathrm{Cr}_{2} \mathrm{O}_{3}$ nanostructure can be expressed by equation (2) as

$$
\mathrm{E}_{\mathrm{ad}}=\left[\mathrm{E}\left(\mathrm{Cr}_{2} \mathrm{O}_{3} / \mathrm{Cl}_{2}\right)-\mathrm{E}\left(\mathrm{Cr}_{2} \mathrm{O}_{3}\right)-\mathrm{E}\left(\mathrm{Cl}_{2}\right)\right]
$$

where $\mathrm{E}\left(\mathrm{Cr}_{2} \mathrm{O}_{3} / \mathrm{Cl}_{2}\right)$ denotes the energy of $\mathrm{Cr}_{2} \mathrm{O}_{3} / \mathrm{Cl}_{2}$ complex, $\mathrm{E}\left(\mathrm{Cr}_{2} \mathrm{O}_{3}\right)$ and $\mathrm{E}\left(\mathrm{Cl}_{2}\right)$ are the isolated energies of $\mathrm{Cr}_{2} \mathrm{O}_{3}$ and $\mathrm{Cl}_{2}$ molecules, respectively. When $\mathrm{Cl}_{2}$ molecules are adsorbed on $\alpha-\mathrm{Cr}_{2} \mathrm{O}_{3}$ material, the positive and negative values of adsorbed energy $\left(\mathrm{E}_{\mathrm{ad}}\right)$ are represented as endothermic and exothermic specificity, respectively. In the present work, positions A, $\mathrm{C}$ and $\mathrm{H}$ have exothermic specificity. This infers that the energies are transferred from $\alpha-\mathrm{Cr}_{2} \mathrm{O}_{3}$ material to $\mathrm{Cl}_{2}$ molecules, which are specified by negative value of adsorbed energy. In contrast, for remaining positions $\mathrm{B}, \mathrm{D}, \mathrm{E}, \mathrm{F}, \mathrm{G}, \mathrm{I}, \mathrm{J}$ and $\mathrm{K}$ belong to endothermic specificity. This depicts that the energies are transferred from $\mathrm{Cl}_{2}$ molecule to $\alpha-\mathrm{Cr}_{2} \mathrm{O}_{3}$ material, which is referred as positive value of adsorbed energy. The $\mathrm{E}_{\mathrm{ad}}$ values of $\alpha-\mathrm{Cr}_{2} \mathrm{O}_{3}$ base material for positions A $\mathrm{K}$ are $-0.54,0.27,-0.54,2.18,0.001,2.72,1.90$, $-0.27,0.27,0.82$ and $2.45 \mathrm{eV}$, respectively. Furthermore, the conductivity of $\alpha-\mathrm{Cr}_{2} \mathrm{O}_{3}$ nanostructure decreases owing to widening of band gap when $\mathrm{Cl}_{2}$ gets adsorbed on $\alpha-\mathrm{Cr}_{2} \mathrm{O}_{3}$ nanostructure, which can be compared with its isolated counterpart. When $\mathrm{Cl}_{2}$ gets adsorbed on positions $\mathrm{A}$ to $\mathrm{K}$ of $\alpha-\mathrm{Cr}_{2} \mathrm{O}_{3}$ nanostructure, the corresponding HOMO-LUMO gap values are 4.28, 4.39, 4.01, 4.04, 4.91, 4.16, 3.01, 3.25, $3.84,4.86$ and $4.79 \mathrm{eV}$. From the observation, it is inferred that the adsorbed energy and HOMO-LUMO gap of $\alpha-\mathrm{Cr}_{2} \mathrm{O}_{3}$ nanostructure varies when $\mathrm{Cl}_{2}$ gets adsorbed on $\alpha-\mathrm{Cr}_{2} \mathrm{O}_{3}$ nanostructure, which indicates 

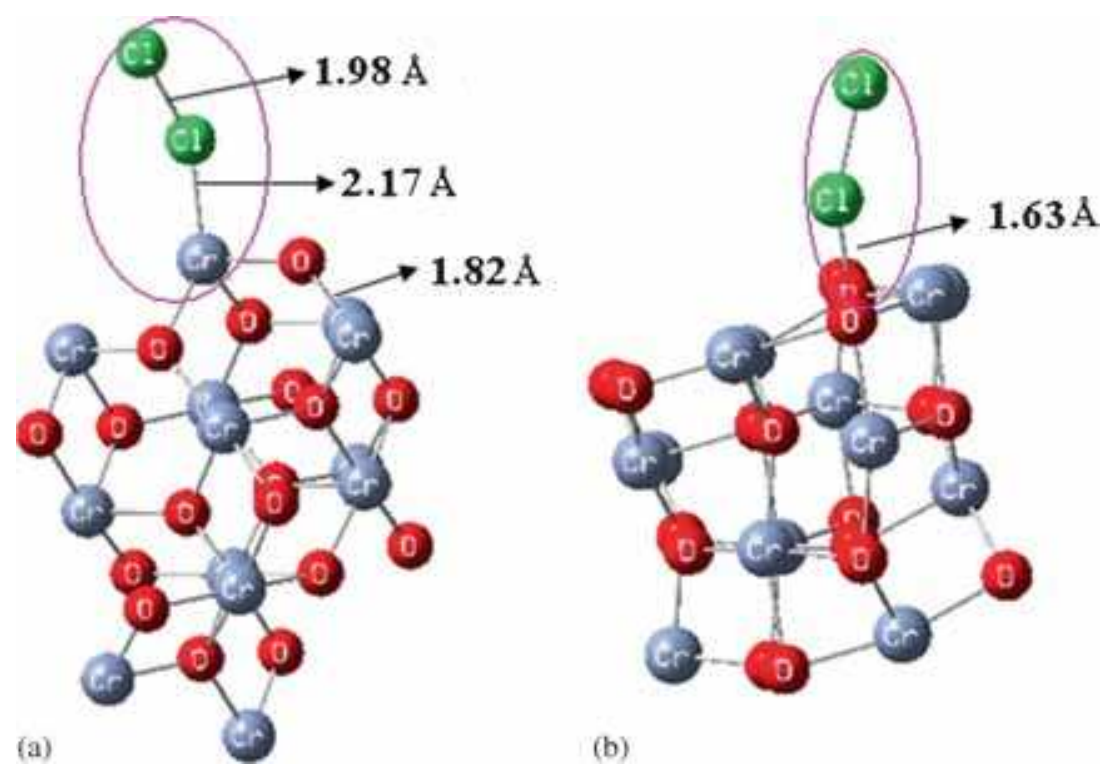

(b)

Figure 4. (a) $\mathrm{Cl}_{2}$ adsorbed on position 'A'; (b) $\mathrm{Cl}_{2}$ adsorbed on position 'B'.

that $\alpha-\mathrm{Cr}_{2} \mathrm{O}_{3}$ nanostructure can be efficiently used to sense $\mathrm{Cl}_{2}$ gas molecule.

Han et al. $^{23}$ reported sodium super ionic conductor (NASICON) based potentiometric $\mathrm{Cl}_{2}$ sensor combining NASICON with $\mathrm{Cr}_{2} \mathrm{O}_{3}$ sensing electrode. In the reported work, authors highlight the sensing performance of $\mathrm{Cl}_{2}$ sensor in air based NASICON and oxide electrode. They report that $\mathrm{Cr}_{2} \mathrm{O}_{3}$ single oxide shows a high sensitivity to chlorine gas in air atmosphere at $300^{\circ} \mathrm{C}$. Nigussa et al. ${ }^{24}$ proposed the adsorption of hydrogen, chlorine, and sulfur on $\alpha-\mathrm{Cr}_{2} \mathrm{O}_{3}$ (0001) surfaces through density functional theory. Chlorine, hydrogen and sulfur get adsorbed on $\mathrm{Cr}_{2} \mathrm{O}_{3}$ and $\mathrm{Cr}$ terminated $\alpha-\mathrm{Cr}_{2} \mathrm{O}_{3}$ surfaces in the reported work. It was reported that $\mathrm{S}$ and $\mathrm{Cl}$ atoms are strongly adsorbed on the surface of $\mathrm{Cr}$ in $\alpha-\mathrm{Cr}_{2} \mathrm{O}_{3}$. The results are in accordance with that of the present work. Balouria et l $^{25}$ give a clear picture on the temperature dependent $\mathrm{H}_{2} \mathrm{~S}$ and $\mathrm{Cl}_{2}$ sensing characteristics on $\mathrm{Cr}_{2} \mathrm{O}_{3}$ thin films. $\mathrm{Cr}_{2} \mathrm{O}_{3}$ thin films are synthesised by electronbeam deposition method and gas sensing properties of $\mathrm{Cr}_{2} \mathrm{O}_{3}$ are studied for various gases namely $\mathrm{CH}_{4}, \mathrm{Cl}_{2}$, $\mathrm{CO}, \mathrm{H}_{2} \mathrm{~S}$ and $\mathrm{NH}_{3}$ at the operating temperature between 30 and $300^{\circ} \mathrm{C}$ with gas concentration in the range of 1-30 ppm. Nigussa et al. reported highly selective $\mathrm{Cl}_{2}$ sensing characteristics on $\mathrm{Cr}_{2} \mathrm{O}_{3}$ at the temperature of $220^{\circ} \mathrm{C}$. In this work, the transfer of electrons between $\alpha-\mathrm{Cr}_{2} \mathrm{O}_{3}$ base material and $\mathrm{Cl}_{2}$ gas molecules leads to change in conductivity. It is observed that the pristine, $\mathrm{Zn}, \mathrm{W}$ and $\mathrm{N}$ substituted $\mathrm{Cr}_{2} \mathrm{O}_{3}$ nanostructures are the prominent base material for sensing chlorine. The most suitable adsorption site of $\mathrm{Cl}_{2}$ gas molecule on $\mathrm{Cr}_{2} \mathrm{O}_{3}$ material can be established only after investigating the percentage of average energy gap variation along with its relative isolated counterpart. Table 3 represents HOMO-LUMO gap, percentage variation in energy gap, adsorbed energy and Mulliken population analysis. From the observation of these results, it is revealed that the most prominent adsorption site of $\mathrm{Cl}_{2}$ gas molecules on $\mathrm{Cr}_{2} \mathrm{O}_{3}$ nanostructure are positions $\mathrm{E}, \mathrm{F}, \mathrm{J}$ and $\mathrm{K}$. The adsorption of $\mathrm{Cl}$ atom in $\mathrm{Cl}_{2}$ molecules adsorbed on $\mathrm{Zn}$ and $\mathrm{Cr}$ in $\mathrm{Zn}$ and $\mathrm{W}$-substituted $\mathrm{Cr}_{2} \mathrm{O}_{3}$ nanostructure, respectively. The average energy gap variation is given by equation (3) as

$$
E_{g}^{a}(\%)=\frac{E g(C r 203 / C l 2)-E g(C r 203)}{E g(C r 203 / C l 2)} \times 100
$$

where $\mathrm{E}_{\mathrm{g}}\left(\mathrm{Cr}_{2} \mathrm{O}_{3} / \mathrm{Cl}_{2}\right)$ is the energy gap of the base material with adsorbed $\mathrm{Cl}_{2}$ and $\mathrm{E}_{\mathrm{g}}\left(\mathrm{Cr}_{2} \mathrm{O}_{3}\right)$ is the energy gap of isolated $\alpha-\mathrm{Cr}_{2} \mathrm{O}_{3}$ base material. Furthermore, the adsorption of $\mathrm{Cl}$ atom in $\mathrm{Cl}_{2}$ molecules adsorbed on both $\mathrm{O}$ and $\mathrm{N}$ in $\mathrm{N}$-substituted $\mathrm{Cr}_{2} \mathrm{O}_{3}$ nanostructure is found to be the most favourable site. Since, the average energy gap variations are recorded high when compared to other adsorption sites.

The transfer of electrons between $\mathrm{Cl}_{2}$ molecule and $\alpha-\mathrm{Cr}_{2} \mathrm{O}_{3}$ material can be analysed by Mulliken population analysis (Q). ${ }^{26-35}$ The negative charge of Mulliken population refers that the electrons are transferred from $\alpha-\mathrm{Cr}_{2} \mathrm{O}_{3}$ material to $\mathrm{Cl}_{2}$ gas molecules and in contrast, the positive charge of $\mathrm{Q}$ depicts the electrons transferred from $\mathrm{Cl}_{2}$ gas molecules to $\alpha-\mathrm{Cr}_{2} \mathrm{O}_{3}$ material. The Mulliken population values of pristine $\alpha-\mathrm{Cr}_{2} \mathrm{O}_{3}$ nanostructure for positions $\mathrm{A}$ and $\mathrm{B}$ are found to be 0.002 and $-0.25 \mathbf{e}$, respectively. In the case of impurity 
Table 3. Adsorbed energy, Mulliken population, HOMO-LUMO gap and average energy gap variation of $\alpha-\mathrm{Cr}_{2} \mathrm{O}_{3}$ nanostructures.

\begin{tabular}{|c|c|c|c|c|c|c|c|}
\hline Nanostructures & $\mathrm{E}_{\mathrm{ad}}(\mathrm{eV})$ & $\mathrm{Q}(\mathrm{e})$ & $\mathrm{E}_{\text {Номо }}$ & $\mathrm{E}_{\mathrm{FL}}(\mathrm{eV})$ & $\mathrm{E}_{\mathrm{LUMO}}$ & $\mathrm{E}_{\mathrm{g}}(\mathrm{eV})$ & $\mathrm{E}_{\mathrm{g}}^{\mathrm{a}} \%$ \\
\hline pristine $\alpha-\mathrm{C}_{2} \mathrm{O}_{3}$ nanostructure & - & - & -5.64 & -3.78 & -1.92 & 3.72 & - \\
\hline A & -0.544 & 0.002 & -6.31 & -4.17 & -2.03 & 4.28 & 13.08 \\
\hline B & 0.272 & -0.254 & -6.85 & -4.65 & -2.46 & 4.39 & 15.26 \\
\hline Zn-substituted $\alpha-\mathrm{C}_{2} \mathrm{O}_{3}$ nanostructure & - & - & -5.37 & -3.36 & -1.35 & 4.02 & - \\
\hline $\mathrm{C}$ & -0.544 & 0.024 & -5.37 & -3.36 & -1.36 & 4.01 & 0.25 \\
\hline $\mathrm{D}$ & 2.176 & -0.242 & -5.84 & -3.82 & -1.8 & 4.04 & 0.5 \\
\hline E & 0.001 & 0.039 & -6.42 & -3.96 & -1.51 & 4.91 & 18.13 \\
\hline W-substituted $\alpha-\mathrm{C}_{2} \mathrm{O}_{3}$ nanostructure & - & - & -6.3 & -4.755 & -3.21 & 3.09 & - \\
\hline $\mathrm{F}$ & 2.72 & 0.085 & -6.48 & -4.4 & -2.32 & 4.16 & 25.72 \\
\hline G & 1.904 & 0.42 & -5.98 & -4.47 & -2.97 & 3.01 & 2.66 \\
\hline $\mathrm{H}$ & -0.272 & -0.218 & -6.26 & -4.63 & -3.01 & 3.25 & 4.92 \\
\hline $\mathrm{N}$-substituted $\alpha-\mathrm{C}_{2} \mathrm{O}_{3}$ nanostructure & - & - & -5.03 & -3.16 & -1.29 & 3.74 & - \\
\hline I & 0.272 & 0.043 & -5.15 & -3.23 & -1.31 & 3.84 & 2.6 \\
\hline $\mathrm{J}$ & 0.816 & -0.224 & -6.87 & -4.44 & -2.01 & 4.86 & 23.05 \\
\hline $\mathrm{K}$ & 2.448 & 0.114 & -6.36 & -3.96 & -1.57 & 4.79 & 21.92 \\
\hline
\end{tabular}

substituted $\alpha-\mathrm{Cr}_{2} \mathrm{O}_{3}$ nanostructures for the positions $\mathrm{C}$, $\mathrm{D}, \mathrm{E}, \mathrm{F}, \mathrm{G}, \mathrm{H}, \mathrm{I}, \mathrm{J}$ and $\mathrm{K}$ have Q values of $0.024,-0.242$, $0.039,0.085,0.42,-0.218,0.043,-0.224$ and $0.114 \mathrm{e}$, respectively. From the observation, positions A, C, E, $\mathrm{F}, \mathrm{G}, \mathrm{I}$ and $\mathrm{K}$ have positive value of $\mathrm{Q}$, which implies that the electrons are transferred from $\mathrm{Cl}_{2}$ to $\alpha-\mathrm{Cr}_{2} \mathrm{O}_{3}$ base material and for the remaining positions $\mathrm{B}, \mathrm{D}, \mathrm{H}$ and $\mathrm{J}$ have negative values of $\mathrm{Q}$, which infers that the electrons are transferred from $\alpha-\mathrm{Cr}_{2} \mathrm{O}_{3}$ base material to $\mathrm{Cl}_{2}$. Almost same negative value of Mulliken charge are recorded for positions $\mathrm{B}, \mathrm{D}, \mathrm{H}$ and $\mathrm{J}$, but the corresponding adsorbed energy values differ. Moreover, with the substitution of $\mathrm{W}$ and $\mathrm{N}$ on $\alpha-\mathrm{Cr}_{2} \mathrm{O}_{3}$ material, $\mathrm{E}_{\mathrm{ad}}$ increases and the corresponding average energy gap variation $\left(\mathrm{E}_{\mathrm{g}}^{\mathrm{a}}\right)$ also increases drastically. This may be due to increase in hole concentration in $\alpha-\mathrm{Cr}_{2} \mathrm{O}_{3}$ base material with the substitution of $\mathrm{W}$ and $\mathrm{N}$. The substitution of $\mathrm{N}$ atoms leads to deficiency of electrons, which in turn increases the p-type behaviour. From the observation it is inferred that $\mathrm{Zn}, \mathrm{W}$ and $\mathrm{N}$-substituted $\alpha-\mathrm{Cr}_{2} \mathrm{O}_{3}$ nanostructures are promising material for $\mathrm{Cl}_{2}$ sensing. Analysing all the parameters such as adsorbed energy, Mulliken population and average energy gap variation for impurity substituted $\alpha-\mathrm{Cr}_{2} \mathrm{O}_{3}$ nanostructures are found to be more probable. The adsorbed energy, average energy gap variation and energy gap for $\mathrm{Zn}$-substituted $\alpha-\mathrm{Cr}_{2} \mathrm{O}_{3}$ nanostructure is significant, even if Mulliken charge transfer is low. Likewise, W and $\mathrm{N}$-substituted $\alpha-\mathrm{Cr}_{2} \mathrm{O}_{3}$ nanostructure also shows favourable adsorption characteristics of $\mathrm{Cl}_{2}$ on $\alpha-\mathrm{Cr}_{2} \mathrm{O}_{3}$
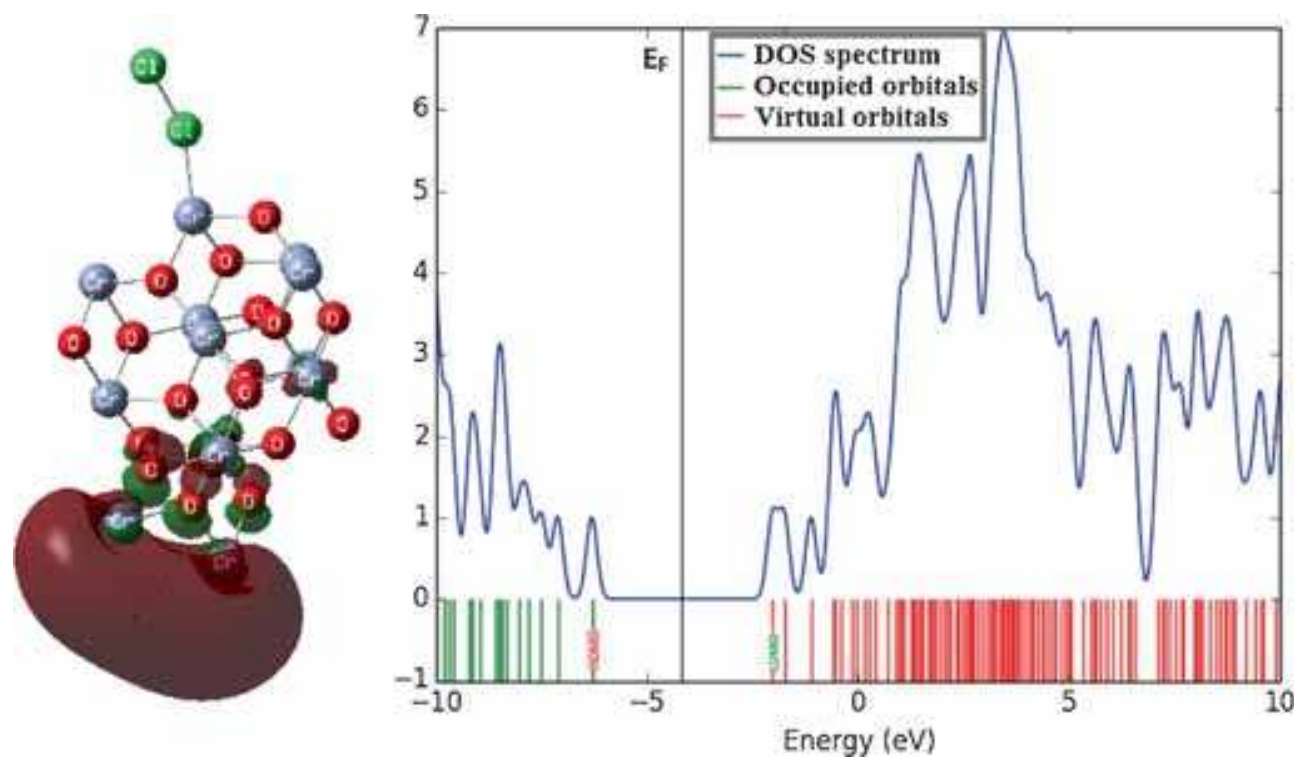

Figure 5. HOMO-LUMO visualization and density of states of $\mathrm{Cl}_{2}$ adsorbed on position $\mathrm{A}$ of $\alpha-\mathrm{Cr}_{2} \mathrm{O}_{3}$ nanostructures. 

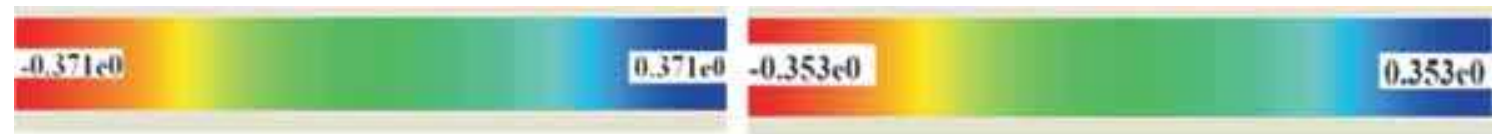

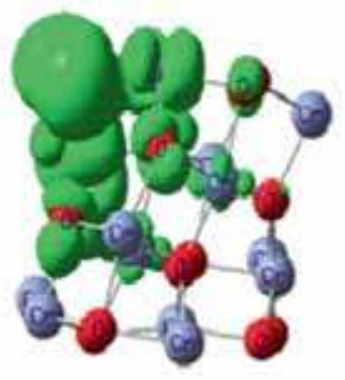

(a)

Figure 6. (a) Electron density of pristine $\alpha-\mathrm{Cr}_{2} \mathrm{O}_{3}$ nanostructure; (b) Electron density of Zn-substituted $\alpha-\mathrm{Cr}_{2} \mathrm{O}_{3}$ nanostructure. nanostructure. The average energy gap variation, adsorbed energy and energy gap is found to be noteworthy. However, in the case of $\mathrm{W}$-substituted $\alpha-\mathrm{Cr}_{2} \mathrm{O}_{3}$ nanostructure, the adsorption properties of $\mathrm{Cl}_{2}$ are not favourable, when $\mathrm{Cl}$ atom in $\mathrm{Cl}_{2}$ molecules adsorbed on $\mathrm{O}$ and $\mathrm{W}$ atoms in $\mathrm{W}$-substituted $\alpha-\mathrm{Cr}_{2} \mathrm{O}_{3}$ nanostructure. Even though the adsorbed energy is more, the average energy gap variation and energy gap is not feasible for $\mathrm{Cl}_{2}$ adsorption. Therefore, the most favourable adsorption sites can be found only after investigation of adsorbed energy, Mulliken population and HOMO LUMO gap of $\alpha-\mathrm{Cr}_{2} \mathrm{O}_{3}$ nanostructure. Figure 5a represents density of states (DOS) spectrum and HOMO LUMO gap of $\mathrm{Cl}_{2}$ adsorbed on $\alpha-\mathrm{Cr}_{2} \mathrm{O}_{3}$ material for position A. The HOMO-LUMO visualization and density of states of $\mathrm{Cl}_{2}$ adsorbed on positions $\mathrm{B}$ to $\mathrm{K}$ of $\alpha$ $\mathrm{Cr}_{2} \mathrm{O}_{3}$ nanostructures are illustrated in supplementary information figure S5, (c)-(k). From the density of states spectrum, it is clearly inferred that the more peak maxima are observed in the virtual orbital rather than the occupied orbital. This implies that the electrons can easily transfer between $\mathrm{Cl}_{2}$ molecule and $\alpha-\mathrm{Cr}_{2} \mathrm{O}_{3}$ material, which can be used as an efficient chemical sensor. Figure 6 (a) and (b) represent the electron density of pristine $\alpha-\mathrm{Cr}_{2} \mathrm{O}_{3}$ and $\mathrm{Zn}$-substituted $\alpha-\mathrm{Cr}_{2} \mathrm{O}_{3}$ nanostructures, respectively. The electron density of W-substituted $\alpha-\mathrm{Cr}_{2} \mathrm{O}_{3}$ nanostructure and $\mathrm{N}$-substituted $\alpha-\mathrm{Cr}_{2} \mathrm{O}_{3}$ nanostructures are shown in supplementary information as figure S6, (c) and (d). Figure 7 depicts the electron density for various positions $\mathrm{A}$ and $\mathrm{B}$ and the electron density of remaining positions $\mathrm{C}$ to $\mathrm{K}$ are shown in figure S7 (c)-(k) in the Supplementary Information. The electron density can be precisely observed with the magnitude of colour gradient. Among all the positions, $\mathrm{E}, \mathrm{F}, \mathrm{J}$ and $\mathrm{K}$ are the most prominent site for $\mathrm{Cl}_{2}$ adsorption on $\alpha-\mathrm{Cr}_{2} \mathrm{O}_{3}$. Since, the corresponding
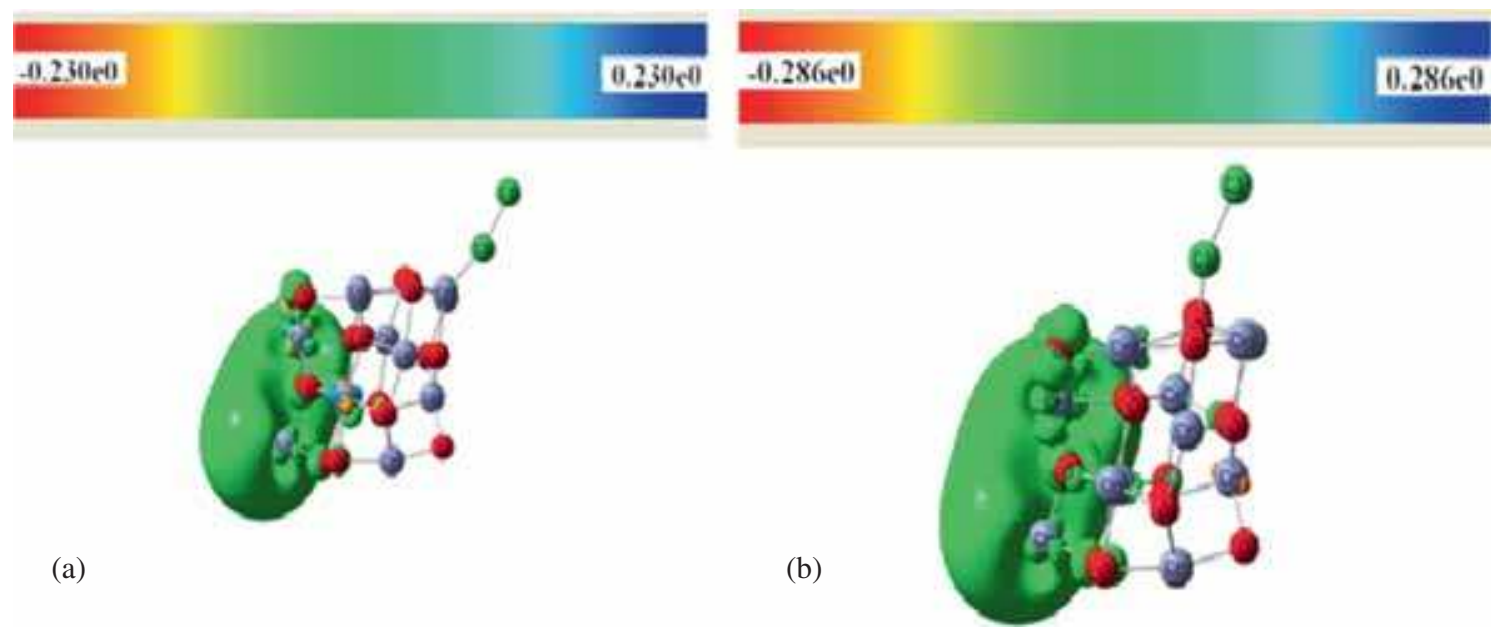

Figure 7. (a) Electron density on position 'A'; (b) Electron density on position 'B'. 
Table 4. Selectivity of $\mathrm{Cl}_{2}$ gas in mixed atmosphere.

\begin{tabular}{lccccccc}
\hline Nanostructures & $\mathrm{E}_{\mathrm{ad}}(\mathrm{eV})$ & $\mathrm{Q}(\mathrm{e})$ & $\mathrm{E}_{\mathrm{HOMO}}$ & $\mathrm{E}_{\mathrm{FL}}(\mathrm{eV})$ & $\mathrm{E}_{\mathrm{LUMO}}$ & $\mathrm{E}_{\mathrm{g}}(\mathrm{eV})$ & $\mathrm{E}_{\mathrm{g}}^{\mathrm{a}} \%$ \\
\hline pristine $\mathrm{Cr}_{2} \mathrm{O}_{3}$ & - & - & -5.64 & -3.78 & -1.92 & 3.72 & - \\
pristine $\mathrm{Cr}_{2} \mathrm{O}_{3}-\mathrm{Cl}_{2}$ & -0.544 & 0.002 & -6.31 & -4.17 & -2.03 & 4.28 & 13.08 \\
pristine $\mathrm{Cr}_{2} \mathrm{O}_{3}-\mathrm{CO}$ & -2.448 & 0.147 & -6.57 & -4.51 & -2.45 & 4.12 & 9.71 \\
pristine $\mathrm{Cr}_{2} \mathrm{O}_{3}-\mathrm{H}_{2} \mathrm{~S}$ & -3.561 & 0.251 & -6.49 & -4.55 & -2.61 & 3.88 & 4.12 \\
pristine $\mathrm{Cr}_{2} \mathrm{O}_{3}-\mathrm{NO}$ & -3.601 & 0.263 & -6.65 & -4.68 & -2.71 & 3.94 & 5.58
\end{tabular}

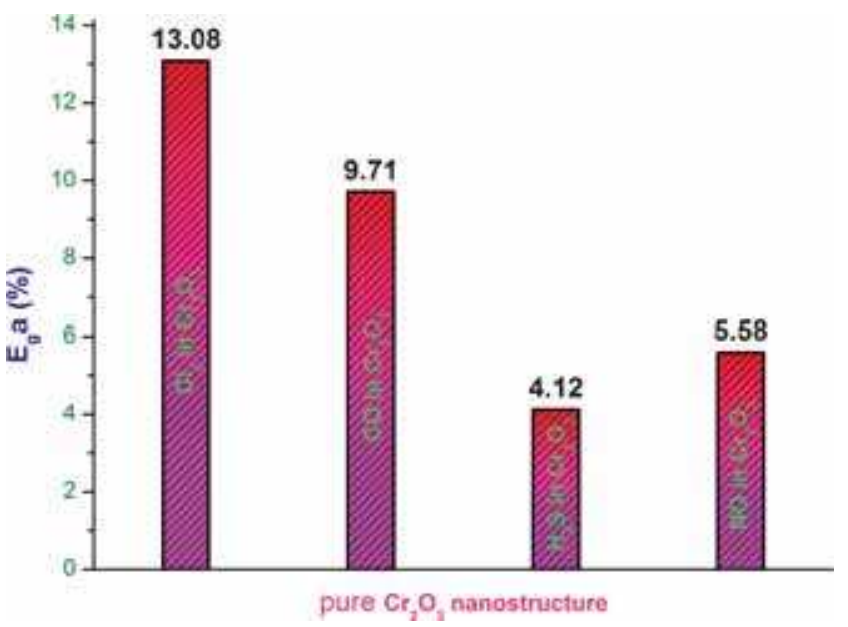

Figure 8. Selectivity of $\mathrm{Cl}_{2}$ in mixed atmosphere.

magnitude value of electron density is high, which is optimum for catalytic behaviour. From all the observations, $\mathrm{Cl}_{2}$ sensing properties can be enhanced with $\mathrm{Zn}$, $\mathrm{W}$ and $\mathrm{N}$ substitution in $\alpha-\mathrm{Cr}_{2} \mathrm{O}_{3}$ base material.

\subsection{Selectivity of $\alpha-\mathrm{Cr}_{2} \mathrm{O}_{3}$ nanostructures}

Selectivity, sensitivity and stability (SSS) are the significant parameters for detection of target gas by the metal oxide nanostructures. Table 4 refers the selectivity of $\mathrm{Cl}_{2}$ gas in the mixed atmosphere. Figure 8 shows precise comparison between $\mathrm{Cl}_{2}$ gas and other gases found in the atmosphere such as $\mathrm{CO}, \mathrm{H}_{2} \mathrm{~S}$ and $\mathrm{NO}$ when get adsorbed on to $\alpha-\mathrm{Cr}_{2} \mathrm{O}_{3}$ base material. As we discussed above the important parameters such as Mulliken charge, energy gap, adsorption energy and average energy gap variation are taken into consideration for finding the selectivity of $\mathrm{Cl}_{2}$ gas in mixed environment. As a result, $\alpha-\mathrm{Cr}_{2} \mathrm{O}_{3}$ nanostructure is selective towards $\mathrm{Cl}_{2}$ gas among other gases namely $\mathrm{CO}, \mathrm{H}_{2} \mathrm{~S}$ and NO. Moreover, the average energy gap variation of $\mathrm{Cl}_{2}$ adsorbed in $\alpha-\mathrm{Cr}_{2} \mathrm{O}_{3}$ material is more when compared to $\mathrm{CO}, \mathrm{H}_{2} \mathrm{~S}$ and $\mathrm{NO}$ adsorbed in $\alpha-\mathrm{Cr}_{2} \mathrm{O}_{3}$ material. Thus, it can be concluded that $\alpha-\mathrm{Cr}_{2} \mathrm{O}_{3}$ nanostructures is a promising material, which can be used as a sensing material for $\mathrm{Cl}_{2}$ gas in mixed gas environment.

\section{Conclusions}

In conclusion, the DFT method is utilized to study the chlorine adsorption characteristics on $\alpha-\mathrm{Cr}_{2} \mathrm{O}_{3}$ material along with B3LYP/ LanL2DZ basis set. The electronic properties and structural stability of pristine, $\mathrm{Zn}$, $\mathrm{W}$ and $\mathrm{N}$-substituted $\alpha-\mathrm{Cr}_{2} \mathrm{O}_{3}$ nanostructures are investigated. The electronic properties of $\alpha-\mathrm{Cr}_{2} \mathrm{O}_{3}$ nanostructures are studied by HOMO-LUMO gap, electron affinity and ionization potential. The structural stability of $\alpha-\mathrm{Cr}_{2} \mathrm{O}_{3}$ nanostructures are illustrated in terms of formation energy. The most prominent adsorption sites of $\mathrm{Cl}_{2}$ on $\alpha-\mathrm{Cr}_{2} \mathrm{O}_{3}$ nanostructures are identified with adsorbed energy, average energy gap variation, Mulliken population analysis and HOMO-LUMO gap. The adsorption characteristics of chlorine on $\alpha-\mathrm{Cr}_{2} \mathrm{O}_{3}$ material can be improved with substitution of $\mathrm{Zn}, \mathrm{W}$ and $\mathrm{N}$ as dopant element in $\alpha-\mathrm{Cr}_{2} \mathrm{O}_{3}$. Thus, the most suitable adsorption site of $\mathrm{Cl}_{2}$ on $\alpha-\mathrm{Cr}_{2} \mathrm{O}_{3}$ nanostructures is when the $\mathrm{Cl}$ atom in $\mathrm{Cl}_{2}$ is adsorbed on $\mathrm{Zn}$ and $\mathrm{Cr}$ in $\mathrm{Zn}$ and $\mathrm{W}$-substituted $\mathrm{Cr}_{2} \mathrm{O}_{3}$ nanostructure, respectively, followed by the $\mathrm{Cl}$ atom in $\mathrm{Cl}_{2}$ adsorbed on both $\mathrm{O}$ and $\mathrm{N}$ in $\mathrm{N}$-substituted $\mathrm{Cr}_{2} \mathrm{O}_{3} . \alpha-\mathrm{Cr}_{2} \mathrm{O}_{3}$ nanostructure is a promising material for sensing $\mathrm{Cl}_{2}$ gas in a mixed gas environment.

\section{Supplementary Information}

Figures $\mathrm{S} 1$ to $\mathrm{S} 7$ are available at www.ias.ac.in/chemsci.

\section{References}

1. Korotcenkov G, Han S H and Cho B K 2013 J. Sensor Sci. Technol. 221

2. Chen P C, Shen G and Zhou C 2008 IEEE Trans. Nanotechnol. 7668

3. Arnold C, Harms M and Goschnick J 2002 IEEE Sens. J. 2179

4. Aswal D K and Gupta S K 2007 In Science and Technology of Chemiresistive Gas Sensors $2^{\text {nd }}$ Ed. (Nova Science Publisher: New York)

5. Moseley P T 1997 Meas. Sci. Technol. 8223

6. Cantalini C 2004 J. Eur. Ceram. Soc. 241421

7. Cellard A V, Garnier G, Fantozzi G, Baret and Fort P 2009 Ceram. Int. 35913 
8. El-Molla S A 2005 Appl. Catal., A 280189

9. Morrison S 1977 J. Catal. 4769

10. Saroha A K 2006 JCHAS 135

11. Frank M, Rivera R and Stashans A 2012 Physica B 407 1262

12. Blacklocks A N, Atkinson A, Packer R J, Savin S L P and Chadwick A V 2006 Solid State Ionics 1772939

13. Dinadayalane T C, Paytakov G and Leszczynski J 2013 J. Mol. Model. 192855

14. Frisch M J, Trucks G W, Schlegel H B, Scuseria G E, Robb M A, Cheeseman J R, Scalmani G, Barone V, Mennucci B, Petersson G A, Nakatsuji H, Caricato $\mathrm{M}$, Li X, Hratchian H P, Izmaylov A F, Bloino J, Zheng G, Sonnenberg J L, Hada M, Ehara, Toyota K, Fukuda R, Hasegawa J, Ishida M, Nakajima T, Honda Y, Kitao O, Nakai H, Vreven T, Montgomery J A, Jr., Peralta J E, Ogliaro F, Bearpark, Heyd J J, Brothers E, Kudin K N, Staroverov V N, Kobayashi R, Normand J, Raghavachari K, Rendell A, Burant J C, Iyengar S S, Tomasi J, Cossi M, Rega N, Millam J M, Klene M, Knox J E, Cross J B, Bakken V, Adamo C, Jaramillo J, Gomperts R, Stratmann R E, Yazyev O, Austin A J, Cammi R, Pomelli C, Ochterski J W, Martin R L, Morokuma K, Zakrzewski V G, Voth G A, Salvador P, Dannenberg J J, Dapprich S, Daniels A D, Farkas Ö, Foresman J B, Ortiz J V, Cioslowski J, and Fox D J 2009 (Gaussian, Inc.: Wallingford CT)

15. Paul K W, Kubicki J D and Sparks D L 2007 Eur. J. Soil Sci. 58978

16. Becke A D 1988 Phys. Rev. A: At. Mol. Opt. Phys. 38 3098

17. Becke A D 1993 J. Chem. Phys. 981372

18. Boyle N M O, Tenderholt A L and Langner K M 2007 J. Comp. Chem. 29839
19. Dutta G, Gupta A, Waghmare U V and Hegde M S 2011 J. Chem. Sci. 123509

20. Sriram S and Chandiramouli R 2013 EPJ Plus 128116

21. Nagarajan V and Chandiramouli R 2014 Alexandria Engineering Journal $\mathbf{5 3} 437$

22. Chandiramouli R and Sriram S 2014 Mater. Sci. Semicond. Process. 27800

23. Zhang Han, Li J, Zhang H, Liang X, Yin C, Diao Q, Zheng J and Lu G 2013 Sens. Actuators B 18066

24. Nigussa K N, Nielsen K L, Borck $\varnothing$ and Støvneng J A 2011 Corros. Sci. 533612

25. Balouria V, Kumar A, Singh A, Samanta S, Debnath A K, Mahajan A, Bedi R K, Aswal D K, Gupta S K and Yakhmi J V 2011 Sens. Actuators B $\mathbf{1 5 7} 466$

26. Mulliken R S 1955 J. Chem. Phys. 231833

27. Csizmadia I G 1976 In Theory and Practice of MO Calculations on Organic Molecules (Elsevier: Amsterdam, Oxford, New York) p. 159

28. Nagarajan V and Chandiramouli R 2014 Ceram. Int. 40 16147

29. Nagarajan V and Chandiramouli R 2014 Comp. Theor. Chem. 104920

30. Nagarajan V and Chandiramouli R 2014 Struct. Chem. 251765

31. Beheshtian J, Zargham B, Mohammad K and Ahmadi A 2011 J. Mol. Model. 182653

32. Beheshtian J, Peyghan A A and Zargham B 2012 Physica E 441963

33. Nagarajan V and Chandiramouli R 2014 J. Inorg. Organomet. Polym. 241038

34. Nagarajan V and Chandiramouli R 2015 J. Inorg. Organomet. Polym. 25837

35. Nagarajan V and Chandiramouli R 2015 Superlattices Microstruct. 7822 